\title{
The Odd Exponentiated Half-Logistic Burr XII Distribution
}

\author{
Maha A. D. Aldahlan \\ Department of Statistics, Faculty of Science - AL Faisaliah Campus \\ King Abdulaziz University, Jeddah, Kingdom of Saudi Arabia \\ maldahlan@kau.edu.sa
}

\author{
Ahmed Z. Afify \\ Department of Statistics, Mathematics and Insurance \\ Benha University, Egypt \\ ahmed.afify@fcom.bu.edu.eg
}

\begin{abstract}
A new lifetime model called the odd exponentiated half-logistic Burr XII distribution is defined and studied. Its density function can be expressed as a linear mixture of Burr XII densities. The proposed model is capable of modeling various shapes of hazard rate including decreasing, increasing, decreasingincreasing-constant, reversed J-shape, J-shape, unimodal or bathtub shapes. Various of its structural properties are investigated. The maximum likelihood method is adopted to estimate the model parameters. The flexibility of the new model is proved empirically using two real data sets. It can serve as an alternative model to other lifetime distributions in the existing literature for modeling positive real data in many areas.
\end{abstract}

Keywords: Burr XII distribution, Maximum likelihood, Moment generating function, Odd exponentiated half-logistic-G family, Order statistics.

\section{Introduction}

The statistical literature contains hundreds of distributions which have several applications in various applied areas such as reliability, engineering, economics, insurance, life testing and biomedical sciences, among other. These applications have indicated that there are many data sets following the classical models are more often the exception rather than the reality. Since, a significant progress has been made towards the generalization of some classical distributions and their successful applications to problems in these areas.

The Burr XII (BXII) distribution (Burr, 1942) with two positive shape parameters, $a$ and $b$, has the cumulative distribution function (CDF) and probability density function (PDF) given (for $x>0$ ) by

$$
G(x ; a, b)=1-\left(1+x^{a}\right)^{-b} \text { and } g(x ; a, b)=a b x^{a-1}\left(1+x^{a}\right)^{-b-1}
$$

The statistical literature contains several generalized forms of the BXII model such as the beta BXII due to Paranaíba et al. (2011), the Kumaraswamy BXII due to Paranaíba et al. (2013), the beta exponentiated BXII due to Mead (2014), the Marshall-Olkin extended BXII due to Al-Saiarie et al. (2014), the McDonald BXII due to Gomes et al. (2015), the exponentiated Burr XII Poisson due to da Silva et al. (2015), the Kumaraswamy exponentiated BXII due to Mead and Afify (2017), the Weibull BXII due to Afify et al. (2018) and the odd Lindley BXII due to Abouelmagd et al. (2018). 
In this paper, we study a new extension of the BXII model called the odd exponentiated half-logistic Burr XII (OEHLBXII) distribution which provides more flexibility in modelling data in several areas. The new model is constructed based on the odd exponentiated half-logistic-G (OEHL-G) family defined by Afify et al. (2017).

Let $G(x ; \xi)$ be a bsaeline CDF with parameter vector $\xi$. Then, the CDF of the OEHL-G class is defined (for $x \in \mathfrak{R}$ ) by

$$
F(x ; \alpha, \lambda, \xi)=\left\{\frac{1-\exp \left[\frac{-\lambda G(x ; \xi)}{1-G(x ; \xi)}\right]}{1+\exp \left[\frac{-\lambda G(x ; \xi)}{1-G(x ; \xi)}\right]}\right\}^{\alpha} .
$$

The corresponding PDF of (2) is given by

$$
f(x ; \alpha, \lambda, \xi)=2 \alpha \lambda g(x ; \xi) \frac{\exp \left[\frac{-\lambda G(x ; \xi)}{1-G(x ; \xi)}\right]\left\{1-\exp \left[\frac{-\lambda G(x ; \xi)}{1-G(x ; \xi)}\right]\right\}^{\alpha-1}}{[1-G(x ; \xi)]^{2}\left\{1+\exp \left[\frac{-\lambda G(x ; \xi)}{1-G(x ; \xi)}\right]\right\}^{\alpha+1}}
$$

where $g(x ; \xi)$ is a bsaeline PDF and $\alpha$ and $\lambda$ are positive shape parameters which provide more flexibility in accommodating all forms of the hazard rate function (HRF) of the generated model.

Now, we define the OEHLBXII distribution and provide some plots for its PDF and HRF. The CDF of the OEHLBXII distribution follows, by inserting the CDF (1) in Equation (2), as

$$
F(x ; \alpha, \lambda, a, b)=\left(\frac{1-\exp \left\{\lambda\left[1-\left(1+x^{a}\right)^{b}\right]\right\}}{1+\exp \left\{\lambda\left[1-\left(1+x^{a}\right)^{b}\right]\right\}}\right)^{\alpha}, x>0 .
$$

The PDF of the OEHLBXII distribution reduces to

$$
f(x ; \alpha, \lambda, a, b)=\frac{2 \alpha \lambda a b x^{a-1} \exp \left\{\lambda\left[1-\left(1+x^{a}\right)^{b}\right]\right\}\left(1-\exp \left\{\lambda\left[1-\left(1+x^{a}\right)^{b}\right]\right\}\right)^{\alpha-1}}{\left(1+x^{a}\right)^{-b+1}\left(1+\exp \left\{\lambda\left[1-\left(1+x^{a}\right)^{b}\right]\right\}\right)^{\alpha+1}},
$$

where $\alpha, \lambda, a$ and $b$ are positive shape parameters which can provide more flexibility to model various data in areas such as survival and lifetime data, engineering, income inequality and others.

The OEHLBXII distribution exhibits all important forms of the HRF including J-shape, reversed J-shape, decreasing, increasing, decreasing-increasing-constant, unimodal or bathtub hazard rate shapes.

The PDF and HRF plots of the OEHLBXII distribution are displayed in Figures 1 and 2, respectively. Figure 1 reveals that the PDF of the OEHLBXII distribution can be reversed J-shape, symmetric, concave down right-skewed or left-skewed. The HRF of the OEHLBXII model can be J-shape, reversed J-shape, decreasing, increasing, unimodal or bathtub hazard rate shapes. 

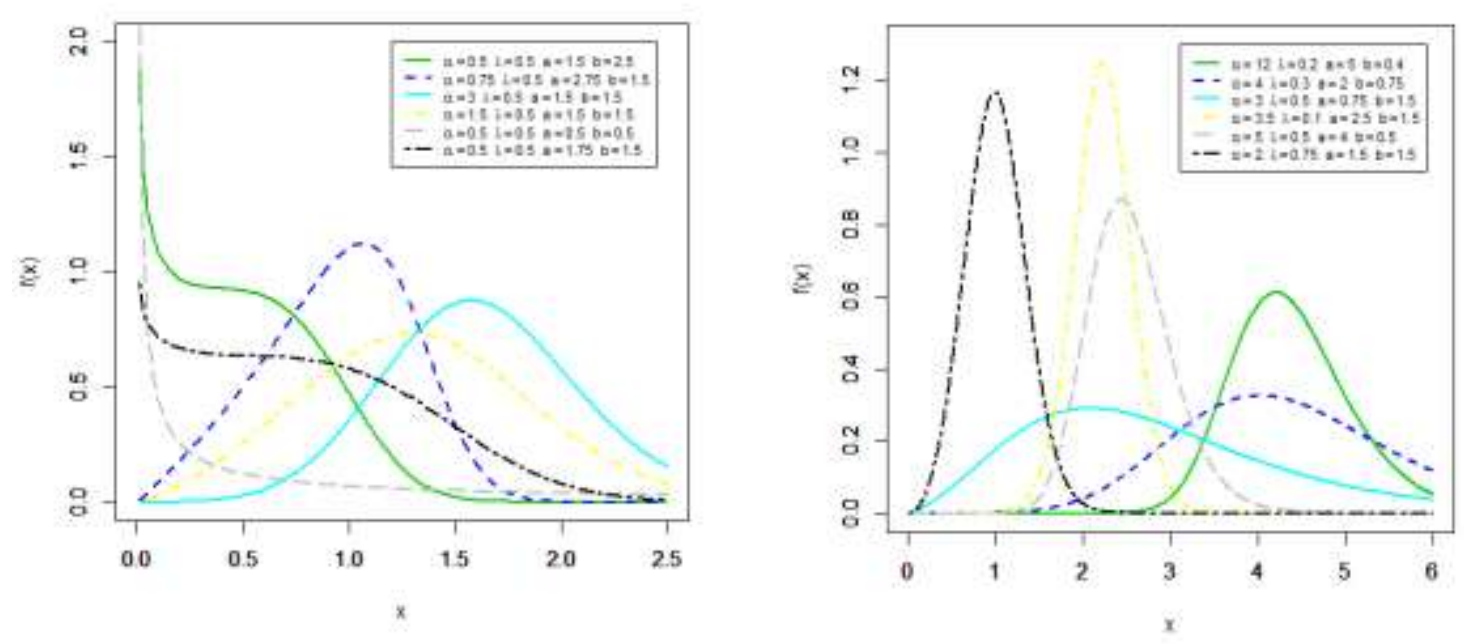

Figure 1: Some possible shapes for the PDF of the OEHLBXII distribution
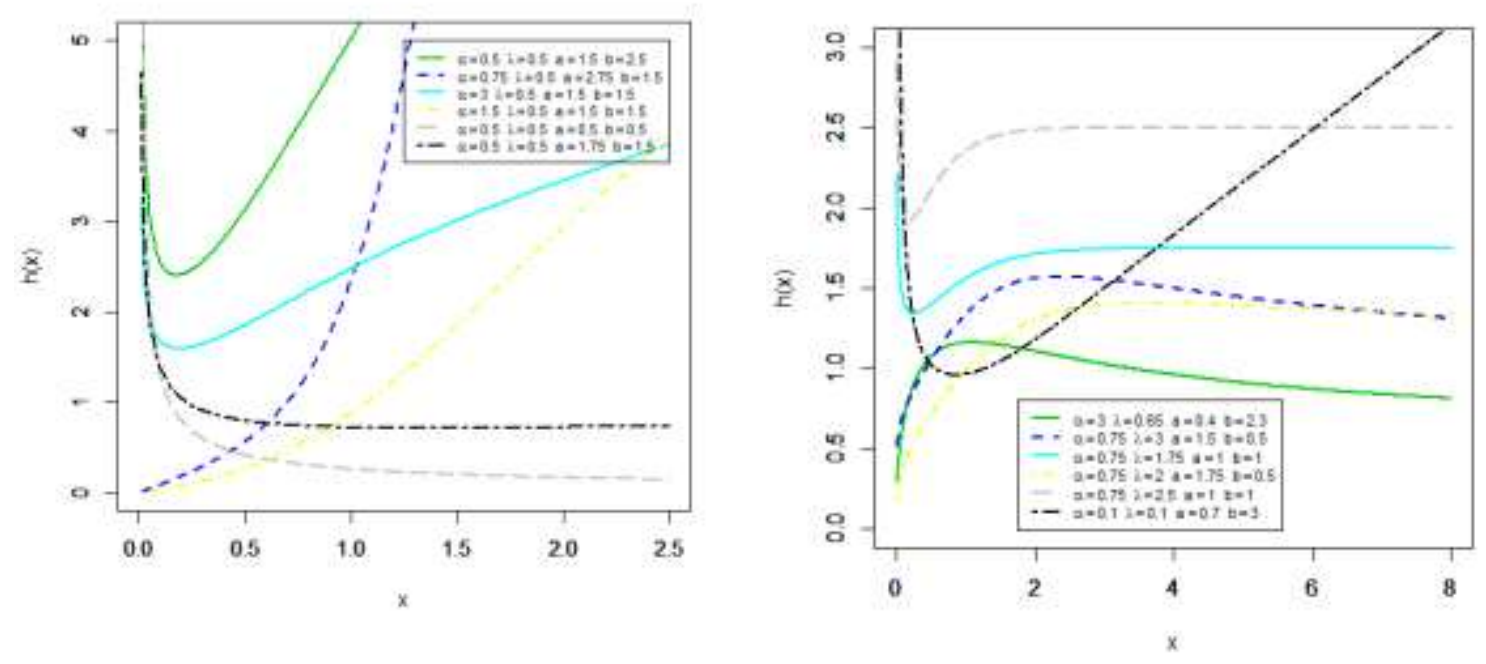

Figure 2: Some possible shapes for the HRF of the OEHLBXII distribution

The rest of the paper is outlined as follows. Section 2, is devoted to derive some mathematical properties of the OEHLBXII distribution. In Section 3, we use maximum likelihood to estimate the model parameters. Two real data sets are analyzed to prove the flexibility of the OEHLBXII model in Section 4. Finally, some concluding remarks are presented in Section 5.

\section{The OEHLBXII properties}

Some properties of the OEHLBXII distribution including linear representation, quantile functoin (QF), ordinary and incomplete moments, moment generating function (MGF), mean residual life (MRL), mean inactivity time (MIT) and order statistics are derived in this section. 


\subsection{Linear representation}

Using Equation (8) in Afify et al. (2017), the PDF of the OEHLBXII distribution can be expressed as

$$
f(x)=\sum_{k, l=0}^{\infty} a_{k, l} h_{k+l+1}(x),
$$

where

$$
a_{k, l}=2 \alpha \lambda \sum_{j, i=0}^{\infty} \frac{(-1)^{j+k+l}[\lambda(j+i+1)]^{k}}{k !(k+l+1)}\left(\begin{array}{c}
-\alpha-1 \\
i
\end{array}\right)\left(\begin{array}{c}
\alpha-1 \\
j
\end{array}\right)\left(\begin{array}{c}
-k-2 \\
l
\end{array}\right)
$$

and $\quad h_{k+l+1}(x)=(k+l+1) a b x^{a-1}\left(1+x^{a}\right)^{-b-1}\left[1-\left(1+x^{a}\right)^{-b}\right]^{k+l} \quad$ is $\quad$ the exponentiated BXII density with power parameter $(k+l+1)$.

Using the generalized binomial expansion, Equation (6) reduces to

$$
f(x)=\sum_{m=0}^{\infty} v_{m} g_{b(m+1)}(x)
$$

where $g_{b(m+1)}(x)=a b(m+1) x^{a-1}\left(1+x^{a}\right)^{-b(m+1)-1}$ is the BXII density with parameters $a$ and $b(m+1)$ and $v_{m}$ is the constant term given by

$$
v_{m}=\sum_{j, i, k, l=0}^{\infty} \frac{(-1)^{j+k+l+m} 2 \alpha \lambda^{k+1}}{k !(m+1)(j+i+1)^{-k}}\left(\begin{array}{c}
\alpha-1 \\
i
\end{array}\right)\left(\begin{array}{c}
\alpha-1 \\
j
\end{array}\right)\left(\begin{array}{c}
-k-2 \\
l
\end{array}\right)\left(\begin{array}{c}
k+l \\
l
\end{array}\right) \text {. }
$$

Equation (7) can be used to derive some properties of the OEHLBXII distributions from those of the BXII distribution.

Let $Y$ be a random variable having the distribution in Equation (1). The $n$th ordinary and incomplete moments of $Y$ are, respectively, given (for $r<a b$ ) by

$$
\begin{aligned}
& \qquad \mu_{n}^{\prime}=b B\left(b-\frac{n}{a}, \frac{n}{a}+1\right) \text { and } \varphi_{n}(t)=b B\left(t^{a} ; b-\frac{n}{a}, \frac{n}{a}+1\right), \\
& B(k, \mathrm{~s})=\int_{0}^{\infty} w^{k-1}(w+1)^{-k-s} d w \text { and } B(t ; k, \mathrm{~s}) \int_{0}^{t} w^{k-1}(w+1)^{-k-s} d w \quad \text { are, } \\
& \text { respectively, the beta and the incomplete beta functions of the second type. }
\end{aligned}
$$

\subsection{Quantile functoin}

The QF of the OEHLBXII distribution, denoted by $Q(u)$, where $0<u<1$, is calculated by solving $F(Q(u))=u$ in (4) for $Q(u)$ in terms of $u$. Then, we have

$$
Q(u)=\left\{\left[1-\frac{-\log \left(1-u^{\frac{1}{\alpha}}\right)+\log \left(1+u^{\frac{1}{\alpha}}\right)}{\lambda-\log \left(1-u^{\frac{1}{\alpha}}\right)+\log \left(1+u^{\frac{1}{\alpha}}\right)}\right]^{\frac{-1}{b}}-1\right\}^{\frac{1}{a}}
$$

\subsection{Some moments}

The $r$ th ordinary moment of $X$, follows from (7) (for $a b(m+1)>r)$ as

$$
\mu_{r}^{\prime}=\sum_{m=0}^{\infty} v_{m} b(m+1) B\left(b(m+1)-\frac{r}{a}, \frac{r}{a}+1\right) .
$$


The mean of $X$ follows by setting $r=1$ in the above equation.

The mean, variance, skewness and kurtosis for different values of $\alpha, \lambda, a$ and $b$ are calculated in Table 1.

Table 1: Mean, variance, skewness and kurtosis of the OEHLBXII model for selected parameter values

\begin{tabular}{ccccllll}
\hline \hline$\alpha$ & $\lambda$ & $a$ & $b$ & Mean & Variance & Skewness & Kurtosis \\
\hline 0.5 & 0.5 & 0.5 & 0.5 & 586.198 & 16325871 & -0.43829 & 0.12761 \\
0.5 & 1.5 & 0.5 & 0.5 & 14.6524 & 5785.34 & 33.3841 & 3932.66 \\
0.5 & 2.5 & 0.5 & 0.5 & 3.23592 & 200.339 & 25.4845 & 2197.98 \\
0.5 & 4.0 & 0.5 & 0.5 & 0.90732 & 11.5900 & 19.1760 & 1163.47 \\
0.5 & 10 & 0.5 & 0.5 & 0.09861 & 0.08711 & 11.5524 & 349.575 \\
\hline 0.5 & 0.5 & 1.5 & 2.5 & 0.50390 & 0.11932 & 0.42536 & 2.37306 \\
0.5 & 1.5 & 1.5 & 2.5 & 0.28190 & 0.04424 & 0.65144 & 2.75647 \\
0.5 & 2.5 & 1.5 & 2.5 & 0.21016 & 0.02618 & 0.74982 & 2.98720 \\
0.5 & 4.0 & 1.5 & 2.5 & 0.15860 & 0.01562 & 0.83029 & 3.20736 \\
0.5 & 10 & 1.5 & 2.5 & 0.08945 & 0.00529 & 0.94961 & 3.59136 \\
\hline 1.5 & 0.5 & 1.5 & 0.5 & 7.52231 & 35.24625 & 1.95525 & 9.67425 \\
2.5 & 0.5 & 1.5 & 0.5 & 9.70655 & 40.56937 & 1.77991 & 8.70444 \\
4.0 & 0.5 & 1.5 & 0.5 & 11.9016 & 44.92013 & 1.67496 & 8.15449 \\
6.0 & 0.5 & 1.5 & 0.5 & 13.9106 & 48.34586 & 1.61195 & 7.82817 \\
10 & 0.5 & 1.5 & 0.5 & 16.56889 & 52.36171 & 1.55452 & 7.52876 \\
\hline 1.5 & 2.5 & 0.5 & 2.0 & 0.11527 & 0.01937 & 2.79773 & 16.06151 \\
1.5 & 2.5 & 1.5 & 2.0 & 0.41878 & 0.03175 & 0.34075 & 2.93500 \\
1.5 & 2.5 & 2.5 & 2.0 & 0.57904 & 0.02442 & -0.16393 & 2.86783 \\
1.5 & 2.5 & 4.0 & 2.0 & 0.70406 & 0.01538 & -0.50166 & 3.31814 \\
1.5 & 2.5 & 10 & 2.0 & 0.86550 & 0.00415 & -0.91961 & 4.48742 \\
\hline 1.5 & 2.5 & 2.5 & 0.5 & 1.22759 & 0.20584 & 0.59692 & 3.70374 \\
1.5 & 2.5 & 2.5 & 1.5 & 0.66278 & 0.03423 & -0.08306 & 2.86930 \\
1.5 & 2.5 & 2.5 & 2.5 & 0.52340 & 0.01917 & -0.21209 & 2.87639 \\
1.5 & 2.5 & 2.5 & 4.0 & 0.42622 & 0.01197 & -0.28382 & 2.90206 \\
1.5 & 2.5 & 2.5 & 10 & 0.29045 & 0.00524 & -0.35499 & 2.94266 \\
\hline \hline
\end{tabular}

This table shows that, for fixed $\alpha, a$ and $b$, the mean and variance are decreasing functions of $\lambda$, while the skewness and kurtosis are increasing functions of $\lambda$. Also, for fixed $\lambda, a$ and $b$, the mean and variance are increasing functions of $\alpha$, while the skewness and kurtosis are decreasing functions of $\alpha$. For fixed $\alpha, \lambda$ and $b$, the mean is increasing function of $a$, while the variance, skewness and kurtosis are decreasing functions of $a$. Further, for fixed $\alpha, \lambda$ and $a$, the mean, variance, skewness and kurtosis are decreasing functions of $b$. It is noted that, the OEHLBXII distribution can be left skewed or right skewed. Then, the OEHLBXII distribution is a flexible distribution that can be used to model skewed data. 
The $r$ th incomplete moment of the OEHLBXII distribution follows from (7) as

$$
\varphi_{r}(t)=\sum_{m=0}^{\infty} v_{m} b(m+1) B\left(t^{a} ; b(m+1)-\frac{r}{a}, \frac{r}{a}+1\right) .
$$

The first incomplete moment of $\boldsymbol{X}$ follows from the last equation, with $\boldsymbol{r}=\mathbf{1}$, as

$$
\varphi_{1}(t)=\sum_{m=0}^{\infty} v_{m} b(m+1) B\left(t^{a} ; b(m+1)-\frac{1}{a}, \frac{1}{a}+1\right)
$$

which is important to calculate the Bonferroni and Lorenz curves and the MRL and MIT. The MRL or life expectancy at age $t$ is defined by

$$
m_{X}(t)=\frac{1-\varphi_{1}(t)}{1-F(t)}-t
$$

Using $\varphi_{1}(t)$, we obtain

$$
m_{X}(t)=\frac{1}{1-F(t)} \sum_{m=0}^{\infty} v_{m} b(m+1) B\left(t^{a} ; b(m+1)-\frac{1}{a}, \frac{1}{a}+1\right)-t
$$

The MIT is defined (for $t>0$ ) by

$$
M_{X}(t)=t-\frac{\varphi_{1}(t)}{F(t)} \text {. }
$$

By inserting $\varphi_{1}(t)$ in the above equation, we have the MIT of $X$ as

$$
M_{X}(t)=t-\frac{1}{F(t)} \sum_{m=0}^{\infty} v_{m} b(m+1) B\left(t^{a} ; b(m+1)-\frac{1}{a}, \frac{1}{a}+1\right) .
$$

\subsection{Moment generating function}

The MGF of $X$ follows from (7) as

$$
M_{X}(t)=\sum_{m=0}^{\infty} v_{m} M_{b(m+1)}(t),
$$

where $M_{b(m+1)}(t)$ is the MGF of the BXII distribution with two parameters $a$ and $b(m+1)$. Paranaíba et al. (2011) provided a simple formula for the MGF of BXII distribution with two-parameter $a$ and $b$ (for $t<0$ ) as

$$
M(t)=s I\left(-t, \frac{s}{b}-1, \frac{s}{b},-b-1\right) .
$$

Combining Equations (8) and (9), the MGF of $X$ reduces to

$$
M_{X}(t)=s \sum_{m=0}^{\infty} v_{m} I\left(-t, \frac{s}{b(m+1)}-1, \frac{s}{b(m+1)},-b(m+1)-1\right)
$$




\subsection{Order statistics}

Let $X_{1}, \ldots, X_{n}$ be a random sample of size $n$ from the OEHLBXII distribution and let $X_{(1)}, \ldots, X_{(n)}$ be the corresponding order statistics. Then, the pdf of the $i$ th order statistic, denoted by $X_{i: n}$, is given by

$$
f_{i: n}(x)=d f(x) \sum_{j=0}^{n-i}(-1)^{j}\left(\begin{array}{c}
n-i \\
j
\end{array}\right) F^{j+i-1}(x),
$$

where $d=n ! /(i-1) !(n-i) !$.

Using Equation (20) in Afify et al. (2017), one can write

$$
\begin{aligned}
f(x) F^{j+i-1}(x)= & \sum_{s, w, k, l=0}^{\infty} \frac{(-1)^{s+k+l} 2 \alpha \lambda^{k+1}}{k !(s+w+1)^{-k}}\left(\begin{array}{c}
\alpha(j+i)-1 \\
s
\end{array}\right)\left(\begin{array}{c}
-\alpha(j+i)-1 \\
w
\end{array}\right)\left(\begin{array}{c}
-k-2 \\
l
\end{array}\right) \\
& \times a b x^{a-1}\left(1+x^{a}\right)^{-b-1}\left[1-\left(1+x^{a}\right)^{-b}\right]^{k+l} .
\end{aligned}
$$

After applying the generalized binomial expansion, the last equation can be expressed as

$$
\begin{aligned}
f(x) F^{j+i-1}(x)= & \sum_{s, w, k, l, m=0}^{\infty} \frac{(-1)^{s+k+l+m} 2 \alpha \lambda^{k+1}}{k !(s+w+1)^{-k}}\left(\begin{array}{c}
\alpha(j+i)-1 \\
s
\end{array}\right)\left(\begin{array}{c}
-\alpha(j+i)-1 \\
w
\end{array}\right) \\
& \times\left(\begin{array}{c}
-k-2 \\
l
\end{array}\right)\left(\begin{array}{c}
k+l \\
m
\end{array}\right) a b x^{a-1}\left(1+x^{a}\right)^{-b(m+1)-1} .
\end{aligned}
$$

By combining the above equation and Equation (10), the PDF of $X_{i: n}$ reduces to

$$
f_{i: n}(x)=\sum_{m=0}^{\infty} u_{m} g_{b(m+1)}(x),
$$

where

$$
\begin{aligned}
& u_{m}=d \sum_{s, w, k, l=0}^{\infty} \sum_{j=0}^{n-i} \frac{(-1)^{j+s+k+l+m} 2 \alpha \lambda^{k+1}}{k !(s+w+1)^{-k}}\left(\begin{array}{c}
n-i \\
j
\end{array}\right) \\
& \times\left(\begin{array}{c}
\alpha(j+i)-1 \\
s
\end{array}\right)\left(\begin{array}{c}
-\alpha(j+i)-1 \\
w
\end{array}\right)\left(\begin{array}{c}
-k-2 \\
l
\end{array}\right)\left(\begin{array}{c}
k+l \\
m
\end{array}\right)
\end{aligned}
$$

and $g_{b(m+1)}$ denotes to the BXII PDF with parameters $a$ and $b(m+1)$.

The $r$ th moment of $X_{i: n}$ follows from Equation (11) as

$$
E\left(X_{i: n}^{r}\right)=\sum_{m=0}^{\infty} u_{m} b(m+1) B\left(b(m+1)-\frac{r}{a}, \frac{r}{a}+1\right) .
$$

\section{Estimation}

The unknown parameters of the OEHLBXII distribution are estimated using the maximum likelihood from complete samples only. Consider a random sample of size $n$, 
$x_{1}, \ldots, x_{n}$, is drawn from this distribution with parameter vector $\boldsymbol{\theta}=(\alpha, \lambda, a, b)^{T}$. Then, the log-likelihood function for $\boldsymbol{\theta}$, denoted by $\ell(\boldsymbol{\theta})$, reduces to

$$
\begin{aligned}
\ell(\boldsymbol{\theta})=n \log (2 \alpha \lambda a b)+(a-1) \sum_{i=1}^{n} \log x_{i}+\lambda \sum_{i=1}^{n} \mathrm{~s}_{i}+(b-1) \sum_{i=1}^{n} \log \left(2-\mathrm{s}_{i}\right) \\
+(\alpha-1) \sum_{i=1}^{n} \log \left[1-\exp \left(\lambda s_{i}\right)\right]-(\alpha+1) \sum_{i=1}^{n} \log \left[1+\exp \left(\lambda \mathrm{s}_{i}\right)\right]
\end{aligned}
$$

where $s_{i}=1-\left(1+x_{i}^{a}\right)^{b}$.

The score vector elements, $\boldsymbol{U}(\boldsymbol{\theta})=\frac{\partial \ell}{\partial \theta}=(U(\alpha), U(\lambda), U(a), U(b))^{T}$, are given by

$$
\begin{gathered}
U(\alpha)=\frac{n}{\alpha}+\sum_{i=1}^{n} \log \left[1-\exp \left(\lambda s_{i}\right)\right]-\sum_{i=1}^{n} \log \left[1+\exp \left(\lambda s_{i}\right)\right], \\
U(\lambda)=\frac{n}{\lambda}+\sum_{i=1}^{n} s_{i}-(\alpha-1) \sum_{i=1}^{n} \frac{s_{i} \exp \left(\lambda s_{i}\right)}{1-\exp \left(\lambda s_{i}\right)}-(\alpha+1) \sum_{i=1}^{n} \frac{s_{i} \exp \left(\lambda s_{i}\right)}{1+\exp \left(\lambda s_{i}\right)} \\
U(a)=\frac{n}{a}+\sum_{i=1}^{n} \log x_{i}-\lambda b \sum_{i=1}^{n} d_{i}+b(b-1) \sum_{i=1}^{n} \frac{d_{i}}{2-s_{i}}+\lambda b(\alpha-1) \sum_{i=1}^{n} \frac{d_{i} \exp \left(\lambda s_{i}\right)}{1-\exp \left(\lambda s_{i}\right)} \\
+\lambda b(\alpha+1) \sum_{i=1}^{n} \frac{d_{i} \exp \left(\lambda s_{i}\right)}{1+\exp \left(\lambda s_{i}\right)}
\end{gathered}
$$

and

$$
\begin{gathered}
U(b)=\frac{n}{b}-\lambda \sum_{i=1}^{n} k_{i}+(b-1) \sum_{i=1}^{n} \frac{k_{i}}{2-s_{i}}+\lambda(\alpha-1) \sum_{i=1}^{n} \frac{k_{i} \exp \left(\lambda s_{i}\right)}{1-\exp \left(\lambda s_{i}\right)} \\
+\lambda(\alpha+1) \sum_{i=1}^{n} \frac{k_{i} \exp \left(\lambda s_{i}\right)}{1+\exp \left(\lambda \mathrm{s}_{i}\right)^{\prime}}
\end{gathered}
$$

where $d_{i}=x_{i}^{a}\left(1+x_{i}^{a}\right)^{b-1} \log x_{i}$ and $k_{i}=\left(1+x_{i}^{a}\right)^{b} \log \left(1+x_{i}^{a}\right)$.

The estimates of the unknown parameters can be obtained by setting the score vector to zero, $\mathbf{U}(\widehat{\boldsymbol{\theta}})=0$. We can get the MLEs $\widehat{\boldsymbol{\theta}}$ by solving the above system of equations simultaneously using numerical method with iterative techniques such as the NewtonRaphson algorithm.

\section{Real data applications}

In this section, the flexibility and importance of the OEHLBXII distribution are illustrated via two real data sets. The first data set consists of 63 observations of the strengths of $1.5 \mathrm{~cm}$ glass fibres, originally obtained by workers at the UK National Physical Laboratory (Smith and Naylor, 1987). The data are: 0.55, 0.74, 0.77, 0.81, 0.84, $0.93,1.04,1.11,1.13,1.24,1.25,1.27,1.28,1.29,1.30,1.36,1.39,1.42,1.48,1.48,1.49$, $1.49,1.50,1.50,1.51,1.52,1.53,1.54,1.55,1.55,1.58,1.59,1.60,1.61,1.61,1.61,1.61$, $1.62,1.62,1.63,1.64,1.66,1.66,1.66,1.67,1.68,1.68,1.69,1.70,1.70,1.73,1.76,1.76$, $1.77,1.78,1.81,1.82,1.84,1.84,1.89,2.00,2.01,2.24$. 
The second data set refers to the remission times (in months) of a random sample of 128 bladder cancer patients (Lee and Wang, 2003). The data are: 0.08, 2.09, 3.48, 4.87, 6.94, $8.66,13.11,23.63,0.20,2.23,3.52,4.98,6.97,9.02,13.29,0.40,2.26,3.57,5.06,7.09$, $9.22,13.80,25.74,0.50,2.46,3.64,5.09,7.26,9.47,14.24,25.82,0.51,2.54,3.70,5.17$, $7.28,9.74,14.76,26.31,0.81,2.62,3.82,5.32,7.32,10.06,14.77,32.15,2.64,3.88,5.32$, $7.39,10.34,14.83,34.26,0.90,2.69,4.18,5.34,7.59,10.66,15.96,36.66,1.05,2.69$, $4.23,5.41,7.62,10.75,16.62,43.01,1.19,2.75,4.26,5.41,7.63,17.12,46.12,1.26,2.83$, $4.33,5.49,7.66,11.25,17.14,79.05,1.35,2.87,5.62,7.87,11.64,17.36,1.40,3.02,4.34$, $5.71,7.93,11.79,18.10,1.46,4.40,5.85,8.26,11.98,19.13,1.76,3.25,4.50,6.25,8.37$, $12.02,2.02,3.31,4.51,6.54,8.53,12.03,20.28,2.02,3.36,6.76,12.07,21.73,2.07,3.36$, $6.93,8.65,12.63,22.69$.

The fits of the OEHLBXII distribution is compared with some competitive models using the Cramér-von Mises $\left(W^{*}\right)$ and Anderson-Darling $\left(A^{*}\right)$ statistics which are used widely for comparing non-nested models. The competitive distributions are the Weibull BXII (WBXII) and beta BXII (BBXII), Kumaraswamy exponentiated BXII (KEBXII), Lindley Weibull (LiW) (Cordeiro et al., 2017), Weibull Fréchet (WFr) (Afify et al., 2016) and BXII distributions whose PDFs are given by

WBXII: $f(x)=a b \alpha \beta x^{\alpha-1} \frac{\left[1-\left(1+x^{\alpha}\right)^{-\beta}\right]^{b-1}}{\left(1+x^{\alpha}\right)^{-\beta b+1}} \exp \left\{-a\left[\left(1+x^{\alpha}\right)^{\beta}-1\right]^{b}\right\}$;

BBXII: $f(x)=\frac{c \theta \beta^{-c}}{B(a, b)} x^{c-1}\left[1+\left(\frac{x}{\beta}\right)^{c}\right]^{-\theta b-1}\left\{1-\left[1+\left(\frac{x}{\beta}\right)^{c}\right]^{-\theta}\right\}^{a-1}$;

KEBXII: $f(x)=\frac{a b c \theta \beta x^{c-1}}{\left(1+x^{c}\right)^{\theta+1}}\left[1-\left(1+x^{c}\right)^{-\theta}\right]^{a \beta-1}\left\{1-\left[1-\left(1+x^{c}\right)^{-\theta}\right]^{a \beta}\right\}^{b-1}$;

LiW: $f(x)=\frac{\theta^{2} \beta}{\theta+1}\left(\alpha^{\beta} x^{\beta-1}+\alpha^{2 \beta} x^{2 \beta-1}\right) \exp \left[-\theta(\alpha x)^{\beta}\right]$;

WFr: $f(x)=a b \beta \alpha^{\beta} x^{-\beta-1} e^{-b\left(\frac{\alpha}{x}\right)^{\beta}}\left\{1-\exp \left[-\left(\frac{\alpha}{x}\right)^{\beta}\right]\right\}^{-b-1} \exp \left(-a\left\{\exp \left[-\left(\frac{\alpha}{x}\right)^{\beta}\right]-\right.\right.$ $\left.1\}^{-b}\right)$

All the above parameters are positive real numbers.

Tables 2 and 3 list the MLEs (corresponding standard errors in parentheses) and the values of $W^{*}$ and $A^{*}$ statistics.

Tables 2 and 3 compare the fits of the OEHLBXII distribution with the WBXII, BBXII, KEBXII, LiW, WFr and BXII distributions. The values in these tables show that the OEHLBXII distribution has the lowest values of $W^{*}$ and $A^{*}$ among all fitted models. So it could be chosen as the best model for both data sets. 
Maha A. D. Aldahlan, Ahmed Z. Afify

Table 2: MLEs (their standard errors in parentheses), $W^{*}$ and $A^{*}$ for glass fibres data

\begin{tabular}{|c|c|c|c|c|c|c|c|}
\hline Model & Estimate & & & & & $W^{*}$ & $A^{*}$ \\
\hline $\begin{array}{l}\text { OEHLBXII } \\
(\alpha, \lambda, a, b)\end{array}$ & $\begin{array}{l}1.0833 \\
(0.472)\end{array}$ & $\begin{array}{l}0.0554 \\
(0.080)\end{array}$ & $\begin{array}{l}2.9437 \\
(2.746)\end{array}$ & $\begin{array}{l}2.0259 \\
(2.171)\end{array}$ & & 0.138 & 0.780 \\
\hline $\begin{array}{l}\text { WBXII } \\
(\alpha, \beta, a, b)\end{array}$ & $\begin{array}{l}1.6077 \\
(0.376)\end{array}$ & $\begin{array}{l}2.7409 \\
(1.010)\end{array}$ & $\begin{array}{c}0.0026 \\
(0.003)\end{array}$ & $\begin{array}{c}1.8888 \\
(0.768)\end{array}$ & & 0.192 & 1.055 \\
\hline $\begin{array}{l}\mathrm{LiW} \\
(\alpha, \beta, \theta)\end{array}$ & $\begin{array}{l}0.7792 \\
(0.182)\end{array}$ & $\begin{array}{r}4.9441 \\
(0.659)\end{array}$ & $\begin{array}{c}0.5349 \\
(0.486)\end{array}$ & & & 0.195 & 1.075 \\
\hline $\begin{array}{l}\mathrm{WFr} \\
(\alpha, \beta, a, b)\end{array}$ & $\begin{array}{r}0.3865 \\
(0.799) \\
\end{array}$ & $\begin{array}{c}0.2436 \\
(0.285) \\
\end{array}$ & $\begin{array}{r}1.4762 \\
(4.782)\end{array}$ & $\begin{array}{r}16.8561 \\
(20.485)\end{array}$ & & 0.277 & 1.485 \\
\hline $\begin{array}{l}\text { KEBXII } \\
(a, b, c, \theta, \beta)\end{array}$ & $\begin{array}{l}4.0220 \\
(24.141)\end{array}$ & $\begin{array}{l}137.8974 \\
(115.511)\end{array}$ & $\begin{array}{r}1.0241 \\
(0.665)\end{array}$ & $\begin{array}{r}1.3285 \\
(1.297)\end{array}$ & $\begin{array}{c}4.0102 \\
(26.065)\end{array}$ & 0.436 & 2.349 \\
\hline $\begin{array}{l}\text { BBXII } \\
(a, b, c, \theta, \beta)\end{array}$ & $\begin{array}{c}26.1629 \\
(14.588)\end{array}$ & $\begin{array}{r}14.7050 \\
(12.885)\end{array}$ & $\begin{array}{r}0.9271 \\
(0.213)\end{array}$ & $\begin{array}{c}5.5864 \\
(5.215)\end{array}$ & $\begin{array}{r}8.2620 \\
(8.132)\end{array}$ & 0.645 & 3.501 \\
\hline $\begin{array}{l}\text { BXII } \\
(a, b)\end{array}$ & $\begin{array}{l}7.4821 \\
(1.285)\end{array}$ & $\begin{array}{l}0.3207 \\
(0.065)\end{array}$ & & & & 1.177 & 7.366 \\
\hline
\end{tabular}

Table 3: MLEs (their standard errors in parentheses), $W^{*}$ and $A^{*}$ for cancer data

\begin{tabular}{|c|c|c|c|c|c|c|c|}
\hline Model & Estima & & & & & $W^{*}$ & $A^{*}$ \\
\hline $\begin{array}{l}\text { OEHLBXII } \\
(\alpha, \lambda, a, b)\end{array}$ & $\begin{array}{l}2.9623 \\
(4.826)\end{array}$ & $\begin{array}{l}0.7077 \\
(1.763)\end{array}$ & $\begin{array}{l}0.5081 \\
(1.138)\end{array}$ & $\begin{array}{l}1.1006 \\
(3.199)\end{array}$ & & 0.032 & 0.213 \\
\hline $\begin{array}{l}\text { WBXII } \\
(\alpha, \beta, a, b)\end{array}$ & $\begin{array}{l}0.789 \\
(0.418)\end{array}$ & $\begin{array}{l}0.2008 \\
(0.312)\end{array}$ & $\begin{array}{l}6.7391 \\
(43.919)\end{array}$ & $\begin{array}{l}2.4552 \\
(1.402)\end{array}$ & & 0.049 & 0.326 \\
\hline $\begin{array}{l}\text { KEBXII } \\
(a, b, c, \theta, \beta)\end{array}$ & $\begin{array}{l}3.0170 \\
(8.796)\end{array}$ & $\begin{array}{l}67.6736 \\
(102.60)\end{array}$ & $\begin{array}{l}0.3383 \\
(0.376)\end{array}$ & $\begin{array}{l}0.8386 \\
(1.674)\end{array}$ & $\begin{array}{l}2.8394 \\
(8.279)\end{array}$ & 0.048 & 0.318 \\
\hline $\begin{array}{l}\text { BBXII } \\
(a, b, c, \theta, \beta)\end{array}$ & $\begin{array}{l}1.0891 \\
(0.451)\end{array}$ & $\begin{array}{l}1.3905 \\
(2.405)\end{array}$ & $\begin{array}{l}1.5728 \\
(0.441)\end{array}$ & $\begin{array}{l}0.8665 \\
(1.017)\end{array}$ & $\begin{array}{l}6.3741 \\
(1.582)\end{array}$ & 0.041 & 0.297 \\
\hline $\begin{array}{l}\text { WFr } \\
(\alpha, \beta, a, b)\end{array}$ & $\begin{array}{l}51.2054 \\
(155.86)\end{array}$ & $\begin{array}{l}0.2206 \\
(0.086)\end{array}$ & $\begin{array}{l}19.5182 \\
(49.010)\end{array}$ & $\begin{array}{l}2.4642 \\
(1.081)\end{array}$ & & 0.062 & 0.405 \\
\hline $\begin{array}{l}\mathrm{LiW} \\
(\alpha, \beta, \theta)\end{array}$ & $\begin{array}{l}0.0171 \\
(0.013) \\
\end{array}$ & $\begin{array}{l}1.0381 \\
(0.068) \\
\end{array}$ & $\begin{array}{c}7.3474 \\
(5.639) \\
\end{array}$ & & & 0.136 & 0.819 \\
\hline $\begin{array}{l}\text { BXII } \\
(a, b)\end{array}$ & $\begin{array}{l}2.3354 \\
(0.354)\end{array}$ & $\begin{array}{l}0.2337 \\
(0.040)\end{array}$ & & & & 0.694 & 5.370 \\
\hline
\end{tabular}

The histogram and the estimated densities for both data sets are displayed in Figures 3 and 4. These plots reveal that the OEHLBXII distribution is the best model to fit both data sets. The fitted PDF, CDF, survival function (SF) and PP plots of the OEHLBXII distribution for both data sets are shown in Figures 5 and 6, respectively. 

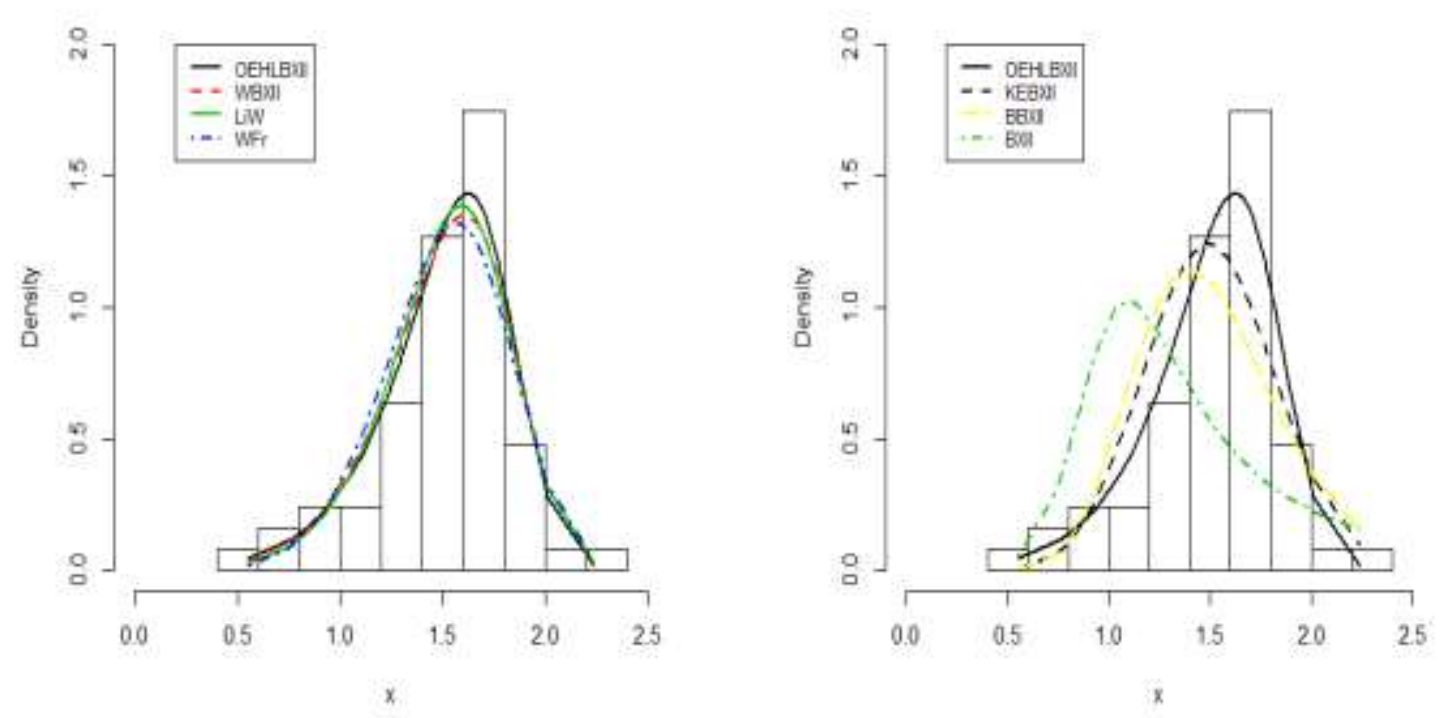

Figure 3: Fitted PDF of the OEHLBXII distribution and other fitted PDFs for glass fibres data
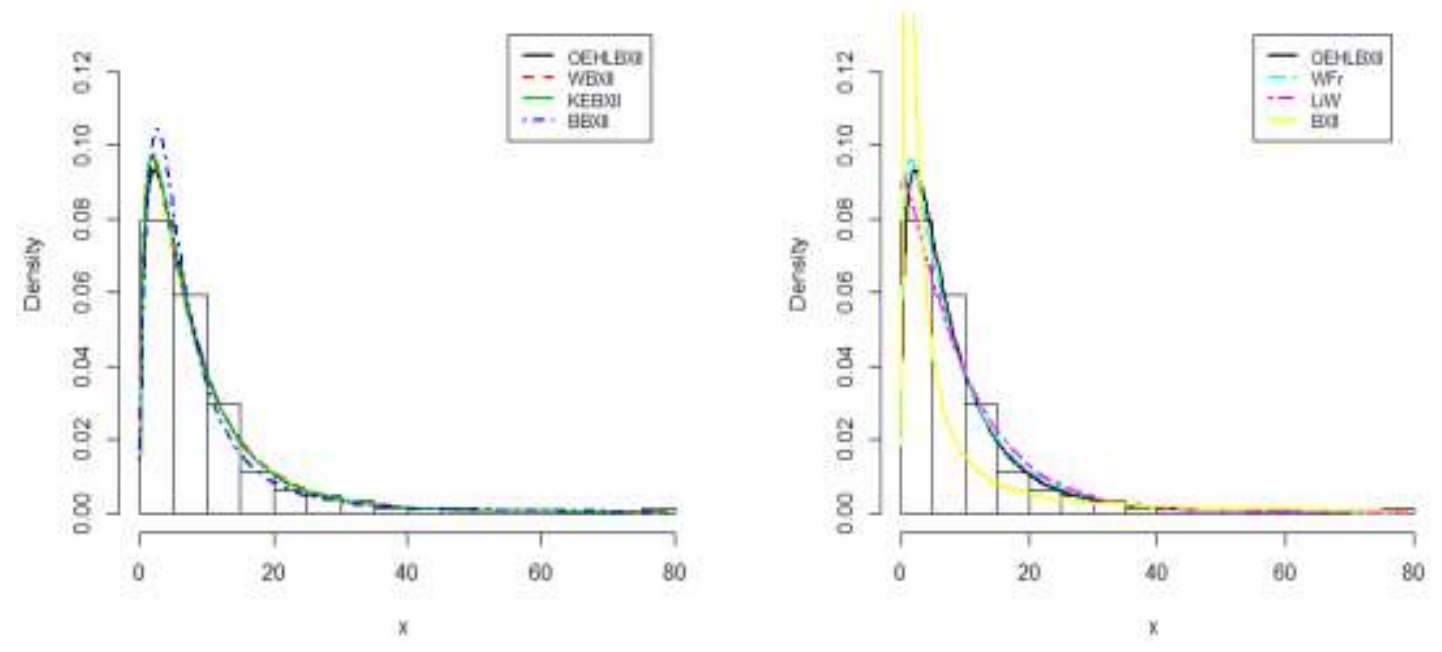

Figure 4: Fitted PDF of the OEHLBXII distribution and other fitted PDFs for cancer data 

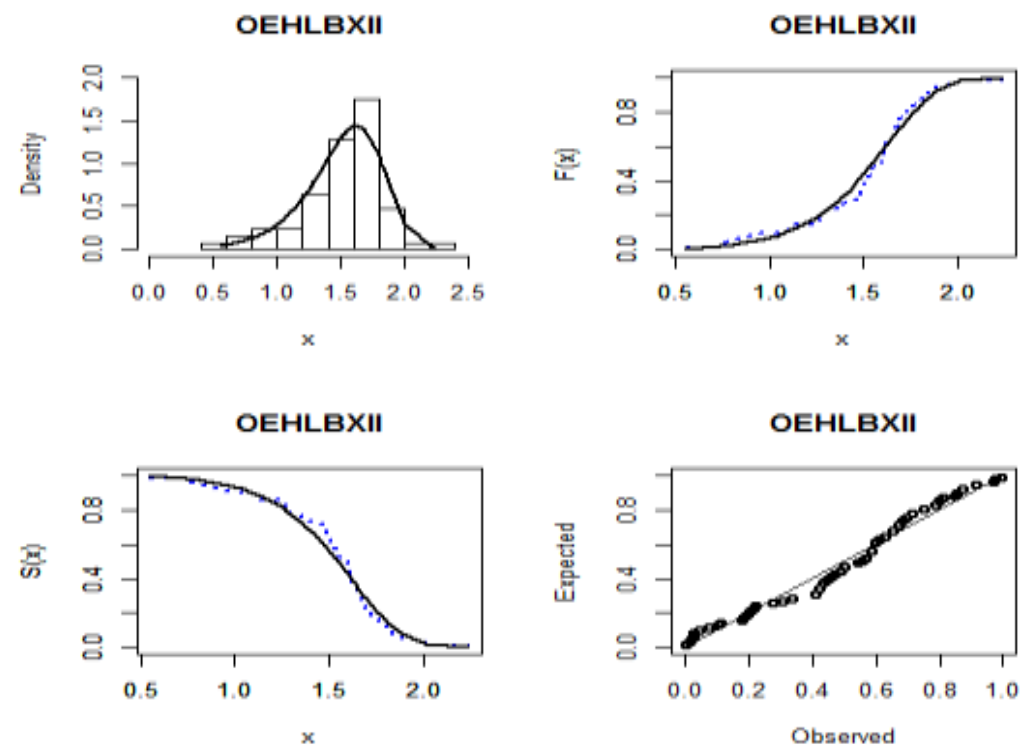

Figure 5: Fitted PDF, CDF, SFand PP plots for glass fibres data
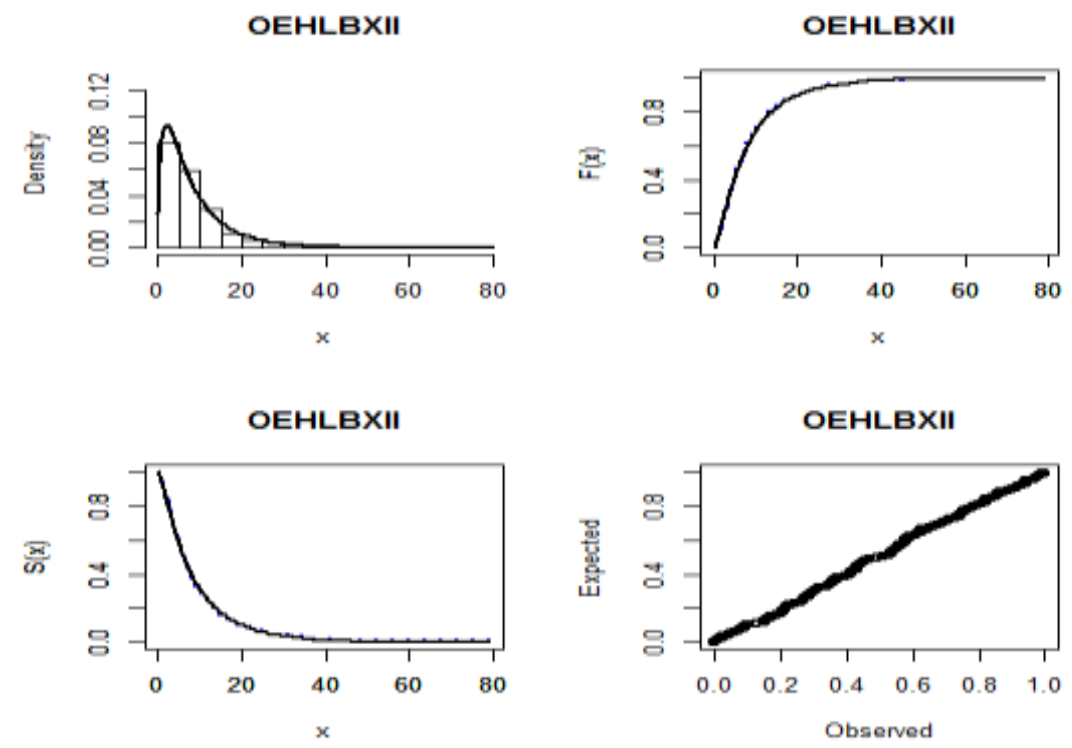

Figure 6: Fitted PDF, CDF, SFand PP plots for cancer data

\section{Conclusions}

We study a new four-parameter model called the odd exponentiated half-logistic Burr XII (OEHLBXII) distribution which generalizes the two-parameter Burr XII distribution. We provide some mathematical properties of the new model including explicit expansions for the quantile function, ordinary and incomplete moments, mean residual life, mean inactivity time and order statistics. The maximum likelihood estimation of the model parameters is investigated. We prove emprically, via two real data applications, that the OEHLBXII distribution can provide better fits than some other well-known competitive models. 


\section{References}

1. Abouelmagd, T. H. M., Al-mualim, S., Afify, A. Z., Ahmad, M. and Al-Mofleh, H. (2018). The odd Lindley Burr XII distribution with applications. Pakistan Journal of Statistics, 34, 15-32.

2. Afify, A. Z., Altun, E., Alizadeh, M., Ozel, G. and Hamedani, G. G. (2017). The odd exponentiated half-logistic-G family: properties, characterizations and applications. Chilean Journal of Statistics, 8, 65-91.

3. Afify, A. Z., Cordeiro, G. M., Ortega, E. M. M., Yousof, H. M. and Butt, N. S. (2018). The four-parameter Burr XII distribution: properties, regression model and applications. Communications in Statistics-Theory and Methods, 47, 26052624.

4. Afify, A. Z., Yousof, H. M., Cordeiro, G. M., Ortega, E. M. M. and Nofal, Z. M. (2016). The Weibull Fréchet distribution and its applications. Journal of Applied Statistics, 43, 2608-2626.

5. Al-Saiari, A. Y., Baharith, L. A. and Mousa, S. A. (2014). Marshall-Olkin extended Burr type XII distribution. International Journal of Statistics and Probability, 3, 78-84.

6. Burr, I. W. (1942). Cumulative frequency functions. Annals of Mathematical Statistics, 13, 215-232.

7. Cordeiro, G. M., Afify, A. Z., Yousof, H. M., Cakmakyapan, S. and Ozel, G. (2017). The Lindley Weibull distribution: properties and applications, Anais da Academia Brasileira de Ciências. To appear.

8. da Silva, R. V., Gomes-Silva, F., Ramos, M. W. A. and Cordeiro, G. M. (2015). The exponentiated Burr XII Poisson distribution with application to lifetime data. International Journal of Statistics and Probability, 4, 112-131.

9. Gomes, A. E., da-Silva, C. Q. and Cordeiro, G. M. (2015). Two extended Burr models: Theory and practice. Communication in Statistics Theory-Methods, 44, 1706-1734.

10. Lee, E. T. and Wang, J. W. (2003). Statistical Methods for Survival Data Analysis. John Wiley and Sons, New York.

11. Mead, M. E. (2014). The beta exponentiated Burr XII distribution. Journal of Statistics: Advances in Theory and Applications, 12, 53-73

12. Mead, M. E. and Afify, A. Z. (2017). On five parameter Burr XII distribution: properties and applications. South African Statistical Journal, 51, 67-80.

13. Paranaíba, P. F., Ortega, E. M. M., Cordeiro, G. M. and de Pascoa, M. (2013). The Kumaraswamy Burr XII distribution: theory and practice. Journal of Statistical Computation and Simulation, 83, 2117-2143.

14. Paranaíba, P. F., Ortega, E. M. M., Cordeiro, G. M. and Pescim, R. R. (2011). The beta Burr XII distribution with application to lifetime data. Computation Statistics and Data Analysis, 55, 1118-1136.

15. Smith, R. L. and Naylor, J. C. (1987). A comparison of maximum likelihood and Bayesian estimators for the three-parameter Weibull distribution, Appl. Statist. 36, 358-369. 